\title{
Association between length of residence and prevalence of MRSA colonization among residents in geriatric long-term care facilities
}

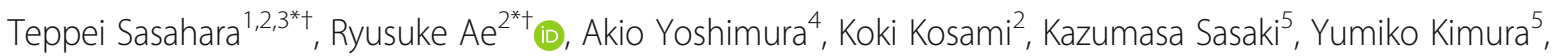
Dai Akine ${ }^{1,6}$, Masanori Ogawa ${ }^{6}$, Kenji Hamabata$^{7}$, Shuji Hatakeyama ${ }^{8}$ and Longzhu Cui ${ }^{3}$

\begin{abstract}
Background: A high prevalence of methicillin-resistant Staphylococcus aureus (MRSA) colonization has been reported among residents in geriatric long-term care facilities (LTCFs). Some studies indicate that MRSA might be imported from hospitals into LTCFs via resident transfer; however, other studies report that high MRSA prevalence might be caused by cross-transmission inside LTCFs. We aimed to assess which factors have a large impact on the high MRSA prevalence among residents of geriatric LTCFs.

Methods: We conducted a cohort study among 260 residents of four geriatric LTCFs in Japan. Dividing participants into two cohorts, we separately analyzed (1) the association between prevalence of MRSA carriage and length of LTCF residence (Cohort 1: $n=204$ ), and (2) proportion of residents identified as MRSA negative who were initially tested at admission but subsequently identified as positive in secondary testing performed at $\geq 2$ months after their initial test (Cohort 2: $n=79$ ).

Results: Among 204 residents in Cohort 1, 20 (9.8\%) were identified as positive for MRSA. Compared with residents identified as MRSA negative, a larger proportion of MRSA-positive residents had shorter periods of residence from the initial admission (median length of residence: 5.5 vs. 2.8 months), although this difference was not statistically significant $(p=0.084)$. Among 79 residents in Cohort 2, 60 (75.9\%) were identified as MRSA negative at the initial testing. Of these 60 residents, only one (1.7\%) had subsequent positive conversion in secondary MRSA testing. In contrast, among 19 residents identified as MRSA positive in the initial testing, 10 (52.6\%) were negative in secondary testing.

* Correspondence: protozoa@jichi.ac.jp; shirouae@jichi.ac.jp

${ }^{\dagger}$ Ryusuke Ae is a co-first author and Teppei Sasahara is a co-corresponding author as well as the first author.

'Division of Clinical Infectious Diseases, School of Medicine, Jichi Medical University, Yakushiji 3311-1, Shimotsuke, Tochigi 329-0498, Japan

2Division of Public Health, Center for Community Medicine, Jichi Medical University, Yakushiji 3311-1, Shimotsuke, Tochigi 329-0498, Japan

Full list of author information is available at the end of the article

C C The Author(s). 2020 Open Access This article is licensed under a Creative Commons Attribution 4.0 International License, which permits use, sharing, adaptation, distribution and reproduction in any medium or format, as long as you give appropriate credit to the original author(s) and the source, provide a link to the Creative Commons licence, and indicate if changes were made. The images or other third party material in this article are included in the article's Creative Commons licence, unless indicated otherwise in a credit line to the material. If material is not included in the article's Creative Commons licence and your intended use is not permitted by statutory regulation or exceeds the permitted use, you will need to obtain permission directly from the copyright holder. To view a copy of this licence, visit http://creativecommons.org/licenses/by/4.0/ The Creative Commons Public Domain Dedication waiver (http://creativecommons.org/publicdomain/zero/1.0/) applies to the data made available in this article, unless otherwise stated in a credit line to the data. 
(Continued from previous page)

Conclusions: The prevalence of MRSA was lower among residents with longer periods of LTCF residence than among those with shorter periods. Furthermore, few residents were found to become MRSA carrier after their initial admission. These findings highlight that MRSA in LTCFs might be associated with resident transfer rather than spread via cross-transmission inside LTCFs.

Keywords: Methicillin-resistant Staphylococcus aureus (MRSA), Older adults, Geriatric long-term care facility, Infection control and prevention

\section{Background}

Admission to geriatric long-term care facilities (LTCFs) is increasingly required for frail older adults in countries with large aging populations. It is challenging to enhance the quality of daily care in these facilities. Particularly, infection prevention and control remain a considerable challenge because frail residents are vulnerable to specific infectious diseases that can cause outbreaks [1-8]. Methicillin-resistant Staphylococcus aureus (MRSA) is one of the most common multidrug-resistant organisms affecting mortality among residents of LTCFs [9-14]. Studies from around the world have reported a wideranging prevalence of MRSA colonization among LTCF residents of 4-65\% [14-24]. This prevalence is much higher than that of the general population, as well as that in hospital settings [25-29], leading to the conclusion that geriatric LTCFs are potential reservoirs for MRSA [24, 29-35].

Several studies using genotyping methods have previously indicated that MRSA is most likely imported from hospitals into LTCFs via the transfer of patients [35-38], which might be associated with the high prevalence of MRSA colonization among LTCF residents. However, other studies have reported that this high prevalence is possibly caused by cross-transmission of MRSA inside LTCFs $[34,39,40]$. In the present study, we aimed to assess which factors have a large impact on the high prevalence of MRSA colonization among residents of LTCFs. We hypothesized that if MRSA spreads from resident to resident inside LTCFs, individuals with longer periods of LTCF residence would have a higher prevalence of MRSA colonization; furthermore, residents in whom MRSA is not detected at the initial LTCF admission would acquire MRSA colonization after admission to an LTCF. To test these hypotheses, we investigated the association between MRSA carriage and length of residence among LTCF residents.

\section{Methods}

\section{Design, settings, and participants}

We conducted a cohort study among residents receiving long-term care in four geriatric LTCFs of Japan. These facilities were selected as they are connected with specific back-up hospitals from which residents are transferred according to their medical needs. The facilities were anonymized owing to the ethics protocol followed; however, the brief profiles of the included LTCFs are listed in Table 1.

In Japan, geriatric LTCFs are classified according to two main types: (1) geriatric health services facilities; and (2) geriatric special nursing homes. The former are intermediate facilities between hospitals and nursing homes, with a primary focus on rehabilitation. These facilities typically have a goal of returning patients to home-based care, although some residents may require long-term care for years. Geriatric special nursing homes provide daily life support, including end-of-life care. We included three geriatric health services facilities and one special nursing home in the study.

Among residents living in these four facilities, study participants were those underwent testing for MRSA carriage during the study period, from August 2018 through March 2020. We divided participants into two cohorts: (1) those residing in an LTCF during the initial 4-month study period (from August 2018 to November 2018), and (2) those who initiated residence in an LTCF throughout the study period (August 2018 to March 2020) (Fig. 1). Residents in Cohort 1 included those who were already residing in an LTCF before the initial study period as well as those who were initially admitted to an LTCF during the period. Therefore, some residents could be included in both cohorts.

\section{Microbiology and MRSA isolates}

Testing for MRSA carriage was performed among residents admitted to an LTCF during the study period. Both nasal cavities of each resident were tested. Each nasal vestibule was swabbed five times, rotating the swab while exerting gentle pressure [41]. Seed-Swab MRSA ${ }^{\text {тм }}$ kits (Eiken Chemical Co., Ltd., Tokyo, Japan.) were used for swabbing and transporting samples [42]. The swabs were moistened with saline solution before each specimen was taken.

Test swabs were streaked onto selective agar plates for MRSA (MDRS-K ${ }^{\mathrm{TN}}$; Kyokuto Pharmaceutical Industrial Co., Ltd., Tokyo, Japan.) and incubated for 24- 
Table 1 Characteristics of facilities

\begin{tabular}{|c|c|c|c|c|}
\hline \multirow[b]{2}{*}{ Characteristics } & \multicolumn{4}{|c|}{ Geriatric long-term care facilities (anonymized) } \\
\hline & A & B & $\mathrm{C}$ & D \\
\hline Facility type & HSF & HSF & $\mathrm{SNH}$ & HSF \\
\hline Resident capacity & 100 & 50 & 60 & 150 \\
\hline Male: Female residents & 47: 53 & 11: 32 & 19: 50 & 33: 67 \\
\hline Age of residents, median (range), year & $84(59-106)$ & $91(77-105)$ & $87(70-106)$ & $85(53-105)$ \\
\hline Population density of municipality where facility is located (persons $\left./ \mathrm{km}^{2}\right)^{\mathrm{a}}$ & 389 & 54 & 389 & 13,370 \\
\hline Region of Japan & Eastern & Eastern & Eastern & Western \\
\hline Number of beds in the back-up hospital & 90 & 100 & 90 & 327 \\
\hline
\end{tabular}

Abbreviations: HSF health services facility, SNH special nursing home

${ }^{\text {a }}$ Calculated using population of the municipalities in 2019 or 2020

$48 \mathrm{~h}$ at $35^{\circ} \mathrm{C}$ [43]. Isolates presumptively identified as MRSA based on colony morphology (mannitol positive, lecithinase-positive yellow colonies) on MDRS-K plates were confirmed as MRSA using a VITEK 2 automated system (bioMerieux, Durham, NC, USA) and oxacillin resistance was tested using the disk diffusion method.

\section{Statistical analyses}

In the first analysis, which was focused on Cohort 1, we assessed the association between carriage status of MRSA (positive/negative) and length of LTCF residence among 204 residents. (Fig. 1, Analysis Part 1). We described the distribution of length of LTCF residence from the initial admission, according to MRSA status.

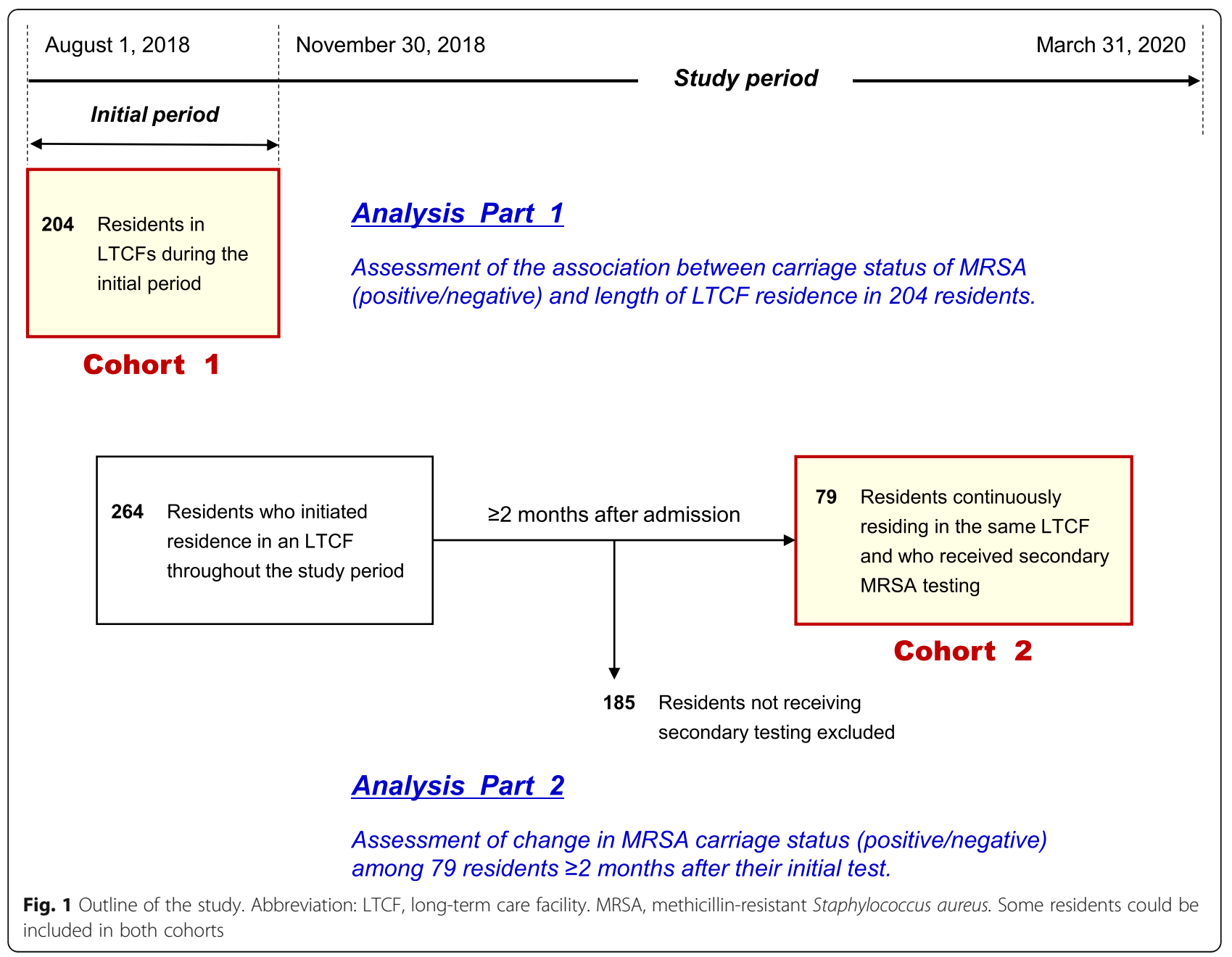


Additionally, we compared the median length of residence from the initial admission, according to MRSA status, using the Mann-Whitney U test.

In the second analysis (Cohort 2), we assessed change in MRSA carriage status among residents $\geq 2$ months after their initial MRSA test (performed $\leq 1$ month after initial admission). For this analysis, we excluded residents who did not undergo a second MRSA test. Among residents who were identified as MRSA negative at their initial admission, we examined the proportion of residents who had converted to positive status at the secondary testing.

All analyses were performed using IBM SPSS Statistics for Windows, Version 25 (IBM Corp., Armonk, NY, USA). Categorical variables are presented as number and percentage whereas numerical variables are presented using median and interquartile range (IQR) unless otherwise indicated. The significance threshold was set at $p<0.05$. This study was approved by the Jichi Medical University Bioethics Committee for Medical Research (Receipt ID: 20-058).

\section{Results}

A total of 260 residents were analyzed. Cohort 1 and Cohort 2 included 204 and 79 residents in the analyses, respectively (Fig. 1). Cohort 1 comprised 93 (45.6\%), 46 (22.5\%), and $65(31.9 \%)$ residents from facilities A, B, and $C$, respectively. No residents from facility $D$ were included in Cohort 1 because none of these residents received MRSA testing during the initial study period. Among 204 residents in Cohort 1, 20 (9.8\%) were identified as positive for MRSA (Table 2). The prevalence of MRSA carriage differed among facilities $(12.9,6.5$, and $7.7 \%$ in facility $\mathrm{A}, \mathrm{B}$, and $\mathrm{C}$, respectively). The median (IQR) length of residence periods was $6(2-15)$ months

Table 2 Basic characteristics of Cohort $1(n=204)$

\begin{tabular}{lll}
\hline & $\mathbf{n}$ & $\mathbf{( \% )}$ \\
\hline MRSA test result & 20 & \\
Positive & 184 & $(9.8)$ \\
Negative & 1 to 114 \\
Length of residence since admission, months & \\
Minimum to maximum & 6 & \\
Median (interquartile range) & 112 & $(2-15)$ \\
$1-6$ & 28 & $(54.9)$ \\
$7-12$ & 22 & $(13.7)$ \\
$13-18$ & 12 & $(10.8)$ \\
$19-24$ & 30 & $(5.9)$ \\
$25+$ & $14.7)$ \\
\hline
\end{tabular}

Abbreviation: MRSA methicillin-resistant Staphylococcus aureus

${ }^{a}$ Measured from admission to the time MRSA testing was performed during

the initial 4-month study period (August 2018 to November 2018) in the Cohort 1, which included 140 (68.6\%) residents with $\leq 1$ year of residence in an LTCF.

Compared with residents identified as MRSA negative, there was a larger proportion of residents with 1-3 months' LTCF residence since initial admission and MRSA-positive status (35.3\% vs 55.0\%) (Fig. 2). Fewer residents with $>1$ year LTCF residence were MRSA positive than MRSA negative ( $20 \%$ vs $33 \%$ ). The median length of residence was shorter among residents identified as MRSA positive than those who were MRSA negative, although a marginally significant association was found between these groups ( 2.8 months vs 5.5 months; $p=0.084$ ) (Fig. 3). These results indicate that residents with shorter periods of LTCF residence were more likely to be MRSA carriers whereas those with longer periods of residence were less likely to have MRSA colonization.

All residents included in Cohort 2 received secondary MRSA testing $\geq 2$ months after their initial test: the median (IQR) testing interval was 3 (2.5-5.5) months (Table 3). Cohort 2 comprised 16 (20.3\%), 9 (11.4\%), 15 (19.0\%), and 39 (49.4\%) residents from facilities A, B, C, and D, respectively. Of 79 residents, 19 (24.1\%) were identified as MRSA positive in their initial test. Among 60 residents identified as MRSA negative in the initial testing, only one (1.7\%) resident subsequently showed positive conversion in the second test (Table 4). In contrast, among 19 residents identified as MRSA positive in the initial testing, $9(47.4 \%)$ remained positive in secondary testing.

\section{Discussion}

Given that MRSA can frequently spread inside geriatric LTCFs via cross-transmission among residents, those with longer periods of residence are considered to have a higher risk for MRSA colonization, which would result in a higher prevalence of MRSA. However, our findings conversely indicated that the prevalence of MRSA was lower among residents with longer residence periods than those with shorter periods. Furthermore, among residents living in LTCFs $\geq 2$ months from their initial admission, only 1 in 60 was identified as having positive conversion to MRSA colonization whereas about half had negative conversion. Findings from previous studies remain controversial as to whether the high prevalence of MRSA among LTCF residents is mainly owing to importation from outside the facility via admission of residents who are colonized with MRSA or whether the high prevalence is owing to cross-transmission inside of LTCFs $[33,34,39,40]$. Our findings indicated that MRSA might be carried into the LTCFs via transfer of residents rather than spread via cross-transmission inside the LTCFs.

Previous studies have reported that among LTCF residents, $20-50 \%$ are potentially persistent nasal MRSA 


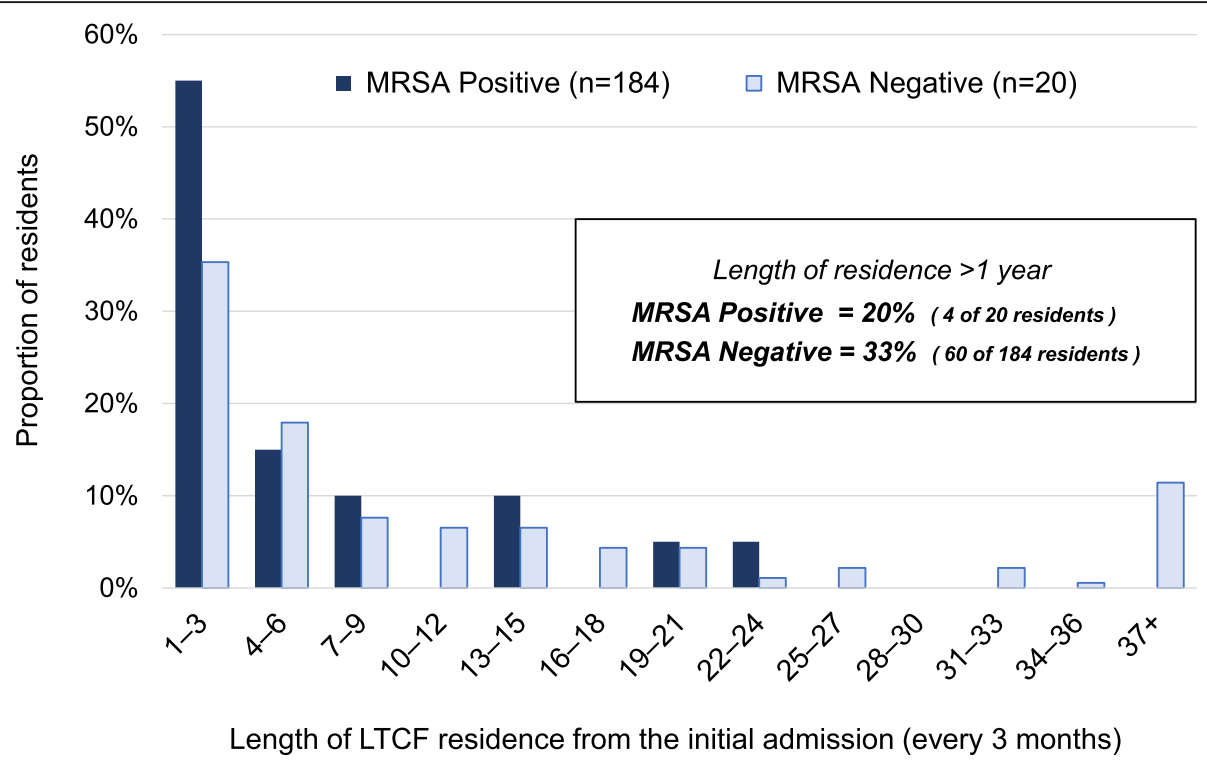

Fig. 2 Resident distributions for length of LTCF residence from the initial admission, according to MRSA colonization $(n=204)$. Abbreviation: LTCF, long-term care facility. MRSA, methicillin-resistant Staphylococcus aureus

carriers, but about $50 \%$ of these residents exhibit negative conversion with time [23, 40]. Another article also indicated that MRSA within the human nasal cavity can disappear over time [22], which is consistent with our results. If residents indeed acquire MRSA via transmission from persistent carriers inside LTCFs, those with longer periods of LTCF residence would be at greater risk for MRSA acquisition, which would prove our hypothesis that LTCF residents with longer periods of residence have a higher prevalence of MRSA. Some previous studies have assumed that geriatric LTCFs are potential reservoirs for MRSA because of the high MRSA prevalence in these facilities [24, 29-35]. However, our study indicated that admission of residents with nasal MRSA colonization might be a primary contributor to the high prevalence of MRSA among LTCF residents.

There are two possible routes via which MRSA may be introduced to LTCFs from outside the facility. The main route would likely be importation from hospitals, which is largely supported by the results of previous studies [35-38]. In addition to these reports, one study previously found that LTCFs with a larger number of hospitals located nearby had a higher prevalence of MRSA than LTCFs with fewer hospitals nearby [44]. Another possible route is via the general population [45]. The prevalence of MRSA in the Japanese general population is estimated to be $\leq 5 \%$ [46-48].; however, this

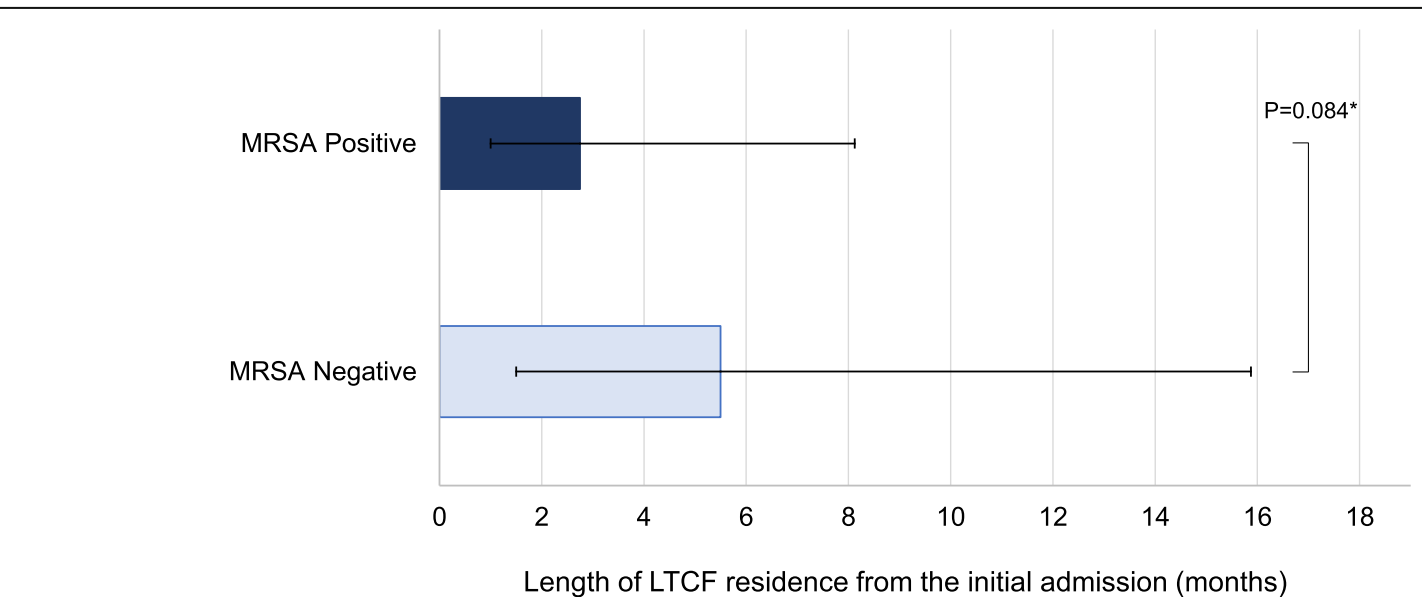

Fig. 3 Median with interquartile range of LTCF residence length from the initial admission, according to MRSA status $(n=204)$. Abbreviation: LTCF, long-term care facility. MRSA, methicillin-resistant Staphylococcus aureus. * Mann-Whitney U test 
Table 3 Basic characteristics of Cohort $2(n=79)$

\begin{tabular}{lll}
\hline & $\mathbf{n}$ & (\%) \\
\hline Initial MRSA test result & \\
$\quad$ Positive & 19 & $(24.1)$ \\
$\quad$ Negative & 60 & $(75.9)$ \\
Second MRSA test result & \\
$\quad$ Positive & 10 & $(12.7)$ \\
Negative & 69 & $(87.3)$ \\
Interval from initial to secondary MRSA testing, months \\
$\quad$ Median (interquartile range) & 3 & $(2.5-5.5)$ \\
\hline
\end{tabular}

Abbreviation: MRSA methicillin-resistant Staphylococcus aureus

a Performed at $\leq 1$ month after residents' initial admission

${ }^{\text {b }}$ Performed $\geq 2$ months after residents' initial test

prevalence might be higher among older adults owing to frailty, in comparison with younger people [49]. Furthermore, regional MRSA epidemics of community-acquired strains have recently occurred in Japan, which might affect MRSA prevalence [45, 48, 50, 51]. A previous study found regional differences in the MRSA prevalence $[44,52]$. Our results showed that the prevalence of MRSA differed among LTCFs, which might reflect differences in the MRSA prevalence among the general population where each LTCF is located.

Care providers in geriatric LTCFs should consider that frail residents who are initially admitted to the facility are most likely to have nasal MRSA colonization, especially those admitted from hospitals. Nasal application of mupirocin for residents identified as having MRSA at the initial admission might be effective for the prevention of MRSA transmission inside an LTCF; however, this should be carefully assessed owing to the high costs as well as the possible increase in MRSA with resistance to mupirocin [53]. Universal precautions against MRSA transmission should therefore be appropriately applied by all LTCF staff. Among various prevention strategies, thorough hand hygiene as well as appropriate use of gloves is recommended to maximize deficient medical resources in LTCFs and to reduce excess costs [54, 55]. Enhanced efforts to prevent the development of decubitus ulcers [56] and wearing gowns and gloves when

Table 4 Conversion of MRSA status in Cohort $2(n=79)$

\begin{tabular}{|c|c|c|c|c|}
\hline & \multicolumn{4}{|c|}{ Initial MRSA test result ${ }^{\mathrm{a}}$} \\
\hline & \multicolumn{2}{|c|}{ Positive $(n=19)$} & \multicolumn{2}{|c|}{ Negative $(n=60)$} \\
\hline & $\mathrm{n}$ & $(\%)$ & $\mathrm{n}$ & $(\%)$ \\
\hline \multicolumn{5}{|c|}{ Second MRSA test result ${ }^{\mathrm{b}}$} \\
\hline Positive $(n=10)$ & 9 & $(47.4)$ & 1 & $(1.7)$ \\
\hline Negative $(n=69)$ & 10 & $(52.6)$ & 59 & $(98.3)$ \\
\hline
\end{tabular}

Abbreviation: MRSA methicillin-resistant Staphylococcus aureus

a Performed at $\leq 1$ month after residents' initial admission

b Performed $\geq 2$ months after residents' initial test caring for residents with indwelling devices, such as a feeding tube or urinary catheter [6], may also be effective in preventing MRSA transmission inside an LTCF. Furthermore, a patient traceability system could be establisehed, with an alarm system between specific back-up hospitals where colonization is alerted and the receiving LTCFs.

This study includes some limitations. First, we did not obtain complete information on the background of residents, such as sex, age, general condition, and medical history owing to the ethics protocol followed; the ethics review board did not grant approval to obtain this information. Among these factors, general status and medical history, including comorbidities, nutritional status, and duration of prior hospitalization, might affect the prevalence of MRSA [49]. Second, we could not obtain information on the prevalence of MRSA carriage in specific regional general populations around each LTCF, as well as among patients hospitalized in each specific back-up hospital, which might affect our results. Third, our study participants included a small number of residents from limited LTCFs. A larger number of residents from a greater number of LTCFs located in both rural and urban regions is required, to further confirm our findings. Fourth, we performed MRSA testing only twice after admission. Multiple tests with longer follow-up might be required to accurately assess the status of MRSA colonization. Fifth, we could not obtain information regarding from where residents had been transferred to the LTCFs. Sixth, not all residents initially admitted to the LTCFs were included in Cohort 2 because some did not agree to undergo secondary MRSA testing. Seventh, we only performed nasal MRSA testing. Some residents have MRSA on their skin or in wound sites, which might result in a higher prevalence. Finally, we did not exclude residents from the analysis who had previously been discharged from an LTCF but who were subsequently readmitted.

\section{Conclusions}

The prevalence of MRSA was lower among residents with longer periods of residence in an LTCF than in those with shorter residence periods. Furthermore, few residents were identified as having positive conversion to MRSA colonization after their initial admission. These findings highlight that MRSA might be carried into LTCFs via the transfer of new residents rather than spread via cross-transmission inside LTCFs. Residents with recent admission to LTCFs might have a large impact on the high prevalence of MRSA.

Abbreviations

MRSA: Methicillin-resistant Staphylococcus aureus; LTCF: Long-term care facility; IQR: Interquartile range 


\section{Acknowledgments}

We thank all the staff of the long-term care facilities who contributed to this study. We also thank Analisa Avila, ELS, of Edanz Group (https://en-authorservices.edanzgroup.com/ac) for editing a draft of this manuscript.

\section{Authors' contributions}

RA, TS, KK, and MO conceptualized and designed the study, carried out the analyses, drafted the initial manuscript, and reviewed and revised the manuscript. RA, TS, DA, MO, KH, SH, and LC conceptualized and designed the study and critically reviewed the manuscript for important intellectual content. TS, AY, RC, and LC designed the data collection instruments, coordinated, and supervised the data collection, and critically reviewed the manuscript. KS, YK, RC, and LC were responsible for microbiological testing and analysis. All authors approved the final manuscript as submitted and agree to be accountable for all aspects of the work.

\section{Funding}

This study was supported by the Japan Agency for Medical Research and Development (AMED) under grant number JP20dk0110030. The funding body had no role in study in the design of the study and collection, analysis, and interpretation of data and in writing the manuscript.

\section{Availability of data and materials}

The datasets used and/or analyzed during the current study are available from the corresponding author on reasonable request.

\section{Ethics approval and consent to participate}

Jichi Medical University Bioethics Committee for Medical Research approved the study and waived the requirement for informed consent of each participant (Receipt ID: 20-058).

\section{Consent for publication}

Not applicable.

\section{Competing interests}

The authors declare that they have no competing interests.

\section{Author details}

'Division of Clinical Infectious Diseases, School of Medicine, Jichi Medical University, Yakushiji 3311-1, Shimotsuke, Tochigi 329-0498, Japan. ${ }^{2}$ Division of Public Health, Center for Community Medicine, Jichi Medical University, Yakushiji 3311-1, Shimotsuke, Tochigi 329-0498, Japan. ${ }^{3}$ Division of Bacteriology, School of Medicine, Jichi Medical University, Yakushiji 3311-1, Shimotsuke, Tochigi 329-0498, Japan. ${ }^{4}$ Medical corporation Sanikukai Nissin Hospital, Kiryu, Gunma 376-0001, Japan. ${ }^{5}$ Clinical Microbiology Laboratory, Jichi Medical University Hospital, Yakushiji 3311-1, Shimotsuke, Tochigi 329-0498, Japan. ${ }^{6}$ Health Service Center, Jichi Medical University, Yakushiji 3311-1, Shimotsuke, Tochigi 329-0498, Japan. ${ }^{7}$ Gerontological Nursing, School of Nursing, Jichi Medical University, Yakushiji 3311-1, Shimotsuke, Tochigi 329-0498, Japan. ${ }^{8}$ Division of Infectious Diseases, Jichi Medical University Hospital, Yakushiji 3311-1, Shimotsuke, Tochigi 329-0498, Japan.

Received: 8 September 2020 Accepted: 9 November 2020 Published online: 18 November 2020

\section{References}

1. Siegel JD, Rhinehart E, Jackson M, Chiarello L. 2007 guideline for isolation precautions: preventing transmission of infectious agents in health care settings. Am J Infect Control. 2007;35(10 Suppl 2):S65-164.

2. Richards $\mathrm{CL}$ Jr. Infection control in long-term care facilities. J Am Med Dir Assoc. 2007;8(3 Suppl):S18-25.

3. Smith PW, Bennett G, Bradley S, Drinka P, Lautenbach E, Marx J, Mody L, Nicolle L, Stevenson K. SHEA/APIC guideline: infection prevention and control in the long-term care facility. Am J Infect Control. 2008;36(7):504-35.

4. Chami K, Gavazzi G, de Wazières B, Lejeune B, Carrat F, Piette F, Hajjar J, Rothan-Tondeur M. Guidelines for infection control in nursing homes: a Delphi consensus web-based survey. J Hosp Infect. 2011;79(1):75-89.

5. Yoshikawa T, Norman DC. Geriatric infectious diseases: current concepts on diagnosis and management. J Am Geriatr Soc. 2017;65(3):631-41.
6. Dumyati G, Stone ND, Nace DA, Crnich CJ, Jump RL. Challenges and strategies for prevention of multidrug-resistant organism transmission in nursing homes. Curr Infect Dis Rep. 2017;19(4):18.

7. Jump RLP, Crnich CJ, Mody L, Bradley SF, Nicolle LE, Yoshikawa TT. Infectious diseases in older adults of long-term care facilities: update on approach to diagnosis and management. J Am Geriatr Soc. 2018;66(4):789803.

8. Sloane PD, Zimmerman S, Nace DA. Progress and challenges in the Management of Nursing Home Infections. J Am Med Dir Assoc. 2020;21 (1): $1-4$.

9. Niclaes L, Buntinx F, Banuro F, Lesaffre E, Heyrman J. Consequences of MRSA carriage in nursing home residents. Epidemiol Infect. 1999;122(2):2359.

10. Bonomo RA. Multiple antibiotic-resistant bacteria in long-term-care facilities: an emerging problem in the practice of infectious diseases. Clin Infect Dis. 2000;31(6):1414-22.

11. Tacconelli E, Pop-Vicas AE, D'Agata EM. Increased mortality among elderly patients with meticillin-resistant Staphylococcus aureus bacteraemia. J Hosp Infect. 2006;64(3):251-6.

12. Vendrell E, Capdevila JA, Barrufet P, Force L, Sauca G, Martínez E, Palomera E, Serra-Prat M, Cornudella J, Llopis A, et al. Mortality among methicillinresistant Staphylococcus aureus carriers in long-term care facilities. Rev Esp Quimioter. 2015;28(2):92-7.

13. Bassetti M, Righi E, Del Giacomo P, Sartor A, Ansaldi F, Trucchi C, Alicino C, Trecarichi EM, Spanu T, Paganino C, et al. Predictors of mortality with Staphylococcus aureus bacteremia in elderly adults. J Am Geriatr Soc. 2018; 66(7):1284-9.

14. Peters C, Dulon M, Kleinmüller O, Nienhaus A, Schablon A. MRSA prevalence and risk factors among health personnel and residents in nursing homes in Hamburg, Germany - a cross-sectional study. PLoS One. 2017;12(1): e0169425.

15. Schwaber MJ, Masarwa S, Navon-Venezia S, Kandlik Y, Chmelnitsky I, Smollan G, Glick R, Neria G, Carmeli Y. High prevalence of methicillinresistant Staphylococcus aureus among residents and staff of long-term care facilities, involving joint and parallel evolution. Clin Infect Dis. 2011; 53(9):910-3.

16. Mossong J, Gelhausen E, Decruyenaere F, Devaux A, Perrin M, Even J, Heisbourg E. Prevalence, risk factors and molecular epidemiology of methicillin-resistant Staphylococcus aureus (MRSA) colonization in residents of long-term care facilities in Luxembourg, 2010. Epidemiol Infect. 2013: 141(6):1199-206.

17. Reynaga E, Torres C, Garcia-Nuñez M, Navarro M, Vilamala A, Puigoriol E, Enrico Lucchetti G, Nunes D, Silva A, Sabrià M. Prevalence of MRSA ST398 carriage in nursing home residents in an area of Spain with a high density of pig farming. Infect Control Hosp Epidemiol. 2018:39(1):90-3.

18. da Silveira M, da Cunha M, de Souza CSM, Correa AAF, Fortaleza C. Nasal colonization with methicillin-resistant Staphylococcus aureus among elderly living in nursing homes in Brazil: risk factors and molecular epidemiology. Ann Clin Microbiol Antimicrob. 2018;17(1):18.

19. Liu CY, Lai CC, Chiang HT, Lu MC, Wang LF, Tsai TL, Kang MY, Jan YN, Lo YT, Ko WC, et al. Predominance of methicillin-resistant Staphylococcus aureus in the residents and environments of long-term care facilities in Taiwan. J Microbiol, Immunol Infection = Wei mian yu gan ran za zhi. 2019;52(1):6274.

20. Kawamura K, Kitaoka K, Kimura K, Wachino Jl, Kondo T, linuma Y, Murakami N, Fujimoto S, Arakawa Y. Spread of seb-positive methicillin-resistant staphylococcus aureus SCCmec type II-ST764 among elderly Japanese in nonacute care settings. Microb Drug Resist. 2019;25(6):915-24.

21. Latour K, Huang TD, Jans B, Berhin C, Bogaerts P, Noel A, Nonhoff C, Dodémont $\mathrm{M}$, Denis $\mathrm{O}$, leven $\mathrm{M}$, et al. Prevalence of multidrug-resistant organisms in nursing homes in Belgium in 2015. PLoS One. 2019;14(3): e0214327.

22. Wertheim HF, Melles DC, Vos MC, van Leeuwen W, van Belkum A, Verbrugh $\mathrm{HA}$, Nouwen JL. The role of nasal carriage in Staphylococcus aureus infections. Lancet Infect Dis. 2005;5(12):751-62.

23. Manzur A, Dominguez MA, Ruiz de Gopegui E, Mariscal D, Gavalda L, Segura F, Perez JL, Pujol M. Natural history of meticillin-resistant Staphylococcus aureus colonisation among residents in community long term care facilities in Spain. J Hosp Infect. 2010;76(3):215-9.

24. Nucleo E, Caltagirone M, Marchetti VM, D'Angelo R, Fogato E, Confalonieri M, Reboli C, March A, Sleghel F, Soelva G, et al. Colonization of long-term 
care facility residents in three Italian provinces by multidrug-resistant bacteria. Antimicrob Resist Infect Control. 2018;7:33.

25. Gorwitz RJ, Kruszon-Moran D, McAllister SK, McQuillan G, McDougal LK, Fosheim GE, Jensen BJ, Killgore G, Tenover FC, Kuehnert MJ. Changes in the prevalence of nasal colonization with Staphylococcus aureus in the United States, 2001-2004. J Infect Dis. 2008;197(9):1226-34.

26. Dulon M, Haamann F, Peters C, Schablon A, Nienhaus A. MRSA prevalence in European healthcare settings: a review. BMC Infect Dis. 2011;11:138.

27. Gamblin J, Jefferies JM, Harris S, Ahmad N, Marsh P, Faust SN, Fraser S, Moore M, Roderick P, Blair I, et al. Nasal self-swabbing for estimating the prevalence of Staphylococcus aureus in the community. J Med Microbiol. 2013;62(Pt 3):437-40.

28. Cheng VC, Tai JW, Wong ZS, Chen JH, Pan KB, Hai Y, Ng WC, Chow DM, Yau MC, Chan JF, et al. Transmission of methicillin-resistant Staphylococcus aureus in the long term care facilities in Hong Kong. BMC Infect Dis. 2013;13:205.

29. Hawkins G, Stewart S, Blatchford O, Reilly J. Should healthcare workers be screened routinely for meticillin-resistant Staphylococcus aureus? A review of the evidence. J Hosp Infect. 2011;77(4):285-9.

30. Barr B, Wilcox MH, Brady A, Parnell P, Darby B, Tompkins D. Prevalence of methicillin-resistant Staphylococcus aureus colonization among older residents of care homes in the United Kingdom. Infect Control Hosp Epidemiol. 2007;28(7):853-9.

31. Nishikawa M, Tanaka T, Nakashima K, Senda K, Shibasaki M, Miura H, Tamakoshi A, Ohta T, Yagi T. Screening for methicillin-resistant Staphylococcus aureus (MRSA) carriage on admission to a geriatric hospital. Arch Gerontol Geriatr. 2009;49(2):242-5.

32. Harrison EM, Ludden C, Brodrick HJ, Blane B, Brennan G, Morris D, Coll F, Reuter S, Brown NM, Holmes MA, et al. Transmission of methicillin-resistant Staphylococcus aureus in long-term care facilities and their related healthcare networks. Genome Med. 2016;8(1):102.

33. Brugnaro P, Fedeli U, Pellizzer G, Buonfrate D, Rassu M, Boldrin C, Parisi SG, Grossato A, Palù G, Spolaore P. Clustering and risk factors of methicillinresistant Staphylococcus aureus carriage in two Italian long-term care facilities. Infection. 2009;37(3):216-21.

34. Eveillard M, Charru P, Rufat P, Hippeaux MC, Lancien E, Benselama F, Branger C. Methicillin-resistant Staphylococcus aureus carriage in a long-term care facility: hypothesis about selection and transmission. Age Ageing. 2008;37(3):294-9.

35. Hudson LO, Reynolds C, Spratt BG, Enright MC, Quan V, Kim D, Hannah P, Mikhail L, Alexander R, Moore DF, et al. Diversity of methicillin-resistant Staphylococcus aureus strains isolated from residents of 26 nursing homes in Orange County, California. J Clin Microbiol. 2013;51(11):3788-95.

36. Albrich WC, Harbarth S. Health-care workers: source, vector, or victim of MRSA? Lancet Infect Dis. 2008;8(5):289-301.

37. Horner C, Parnell P, Hall D, Kearns A, Heritage J, Wilcox M. Meticillin-resistant Staphylococcus aureus in elderly residents of care homes: colonization rates and molecular epidemiology. J Hosp Infect. 2013;83(3):212-8.

38. Lee BY, Bartsch SM, Wong KF, Singh A, Avery TR, Kim DS, Brown ST, Murphy CR, Yilmaz SL, Potter MA, et al. The importance of nursing homes in the spread of methicillin-resistant Staphylococcus aureus (MRSA) among hospitals. Med Care. 2013;51(3):205-15.

39. Stine OC, Burrowes S, David S, Johnson JK, Roghmann MC. Transmission clusters of methicillin-resistant Staphylococcus Aureus in long-term care facilities based on whole-genome sequencing. Infect Control Hosp Epidemiol. 2016;37(6):685-91.

40. Stone ND, Lewis DR, Johnson TM 2nd, Hartney T, Chandler D, Byrd-Sellers J, McGowan JE Jr, Tenover FC, Jernigan JA, Gaynes RP. Methicillin-resistant Staphylococcus aureus (MRSA) nasal carriage in residents of veterans affairs long-term care facilities: role of antimicrobial exposure and MRSA acquisition. Infect Control Hosp Epidemiol. 2012;33(6):551-7.

41. Warnke P, Harnack T, Ottl P, Kundt G, Podbielski A. Nasal screening for Staphylococcus aureus--daily routine with improvement potentials. PLoS One. 2014;9(2):e89667.

42. Sasaki T, Kikuchi K, Tanaka Y, Takahashi N, Kamata S, Hiramatsu K. Methicillin-resistant Staphylococcus pseudintermedius in a veterinary teaching hospital. J Clin Microbiol. 2007:45(4):1118-25.

43. Sumitani $Y$, Kobayashi $Y$. Comparative evaluation of a rapid MRSA detection assay based on multiplex real-time PCR versus MRSA screening cultures containing egg yolk. J Infect Chemother. 2009;15(4):262-5.

44. Cheatham S, Thapaliya D, Taha M, Milliken K, Dalman MR, Kadariya J, Grenier D, Smith TC. Prevalence of Staphylococcus aureus and methicillin-resistant S aureus on environmental surfaces in Ohio nursing homes. Am J Infect Control. 2019;47(12):1415-9.
45. Murphy CR, Hudson LO, Spratt BG, Quan V, Kim D, Peterson E, Tan G, Evans $\mathrm{K}$, Meyers $\mathrm{H}$, Cheung $\mathrm{M}$, et al. Predicting high prevalence of community methicillin-resistant Staphylococcus aureus strains in nursing homes. Infect Control Hosp Epidemiol. 2013;34(3):325-6.

46. Yamasaki F, Takeuchi S, Uehara Y, Matsushita M, Arise K, Morimoto N, Seo H. Prevalence and characteristics of methicillin-resistant Staphylococcus aureus in community residents of Japan. J Gen Fam Med. 2018;19(3):77-81.

47. Mizuno $Y$, Shirahashi K, Yamamoto H, Matsumoto M, Miyamoto Y, Komuro $\mathrm{H}$, Doi K, Iwata H. Preoperative screening for nasal carriage of methicillinresistant Staphylococcus aureus in patients undergoing general thoracic surgery. J Rural Med. 2019;14(1):73-7.

48. Hisata K, Ito T, Matsunaga N, Komatsu M, Jin J, Li S, Watanabe S, Shimizu T, Hiramatsu K. Dissemination of multiple MRSA clones among communityassociated methicillin-resistant Staphylococcus aureus infections from Japanese children with impetigo. J Infect Chemother. 2011;17(5):609-21.

49. Romaniszyn D, Pobiega M, Wójkowska-Mach J, Chmielarczyk A, Gryglewska B, Adamski P, Heczko PB, Ochońska D, Bulanda M. The general status of patients and limited physical activity as risk factors of methicillin-resistant Staphylococcus aureus occurrence in long-term care facilities residents in Krakow, Poland. BMC Infect Dis. 2014;14:271.

50. Uehara Y, Sasaki T, Baba T, Lu Y, Imajo E, Sato Y, Tanno S, Furuichi M, Kawada M, Hiramatsu K. Regional outbreak of community-associated methicillin-resistant Staphylococcus aureus ST834 in Japanese children. BMC Infect Dis. 2019;19(1):35.

51. Yanagihara K, Araki N, Watanabe S, Kinebuchi T, Kaku M, Maesaki S, Yamaguchi K, Matsumoto T, Mikamo H, Takesue Y, et al. Antimicrobial susceptibility and molecular characteristics of 857 methicillin-resistant Staphylococcus aureus isolates from 16 medical centers in Japan (20082009): nationwide survey of community-acquired and nosocomial MRSA. Diagn Microbiol Infect Dis. 2012;72(3):253-7.

52. Manzur A, Gavalda L, Ruiz de Gopegui E, Mariscal D, Dominguez MA, Perez $J$, Segura F, Pujol M. Prevalence of methicillin-resistant Staphylococcus aureus and factors associated with colonization among residents in community long-term-care facilities in Spain. Clin Microbiol Infect. 2008; 14(9):867-72.

53. Mody L, Kauffman CA, McNeil SA, Galecki AT, Bradley SF. Mupirocin-based decolonization of Staphylococcus aureus carriers in residents of 2 long-term care facilities: a randomized, double-blind, placebo-controlled trial. Clin Infect Dis. 2003;37(11):1467-74.

54. Chuang WW, Tsang IH, Keung JP, Leung JY, Yuk JM, Wong DK, Au SS, Tam RK, Lam WW, Kwan MC, et al. Infection control intervention on meticillin resistant Staphylococcus aureus transmission in residential care homes for the elderly. J Infect Prev. 2015;16(2):58-66.

55. Matsumoto K, Shigemi A, Yaji K, Shimodozono Y, Takeda Y, Ikawa K, Morikawa N, Miyanohara H, Kawamura H, Orita M, et al. Reduction in the incidence of MRSA with use of alcohol-based hand rub solutions and gloves. J Infect Chemother. 2012;18(2):269-71.

56. Manzur A, Gudiol F. Methicillin-resistant Staphylococcus aureus in longterm-care facilities. Clin Microbiol Infect. 2009;15(Suppl 7):26-30.

\section{Publisher's Note}

Springer Nature remains neutral with regard to jurisdictional claims in published maps and institutional affiliations.

\section{Ready to submit your research? Choose BMC and benefit from:}

- fast, convenient online submission

- thorough peer review by experienced researchers in your field

- rapid publication on acceptance

- support for research data, including large and complex data types

- gold Open Access which fosters wider collaboration and increased citations

- maximum visibility for your research: over $100 \mathrm{M}$ website views per year

At BMC, research is always in progress.

Learn more biomedcentral.com/submissions 